\title{
The radial artery: An important component of multiarterial coronary surgery and considerations for its optimal harvest
}

James Tatoulis, AM, MB, BS, MS, MD, FRACS, FRCST, FCSANZ

There is mounting evidence from large observational studies and randomized trials (RCTs) that coronary artery bypass grafting using multiple arterial grafts (MAG) results in superior graft patency and better long-term clinical outcomes without compromising perioperative mortality and morbidity. ${ }^{1-3}$

The radial artery (RA) has emerged as the second arterial graft of choice. It has the same patency as the right internal thoracic artery (ITA) when placed to the same vessels under the same conditions, but is much more versatile and easier to use. ${ }^{4}$

Introduced in 1971 by Carpentier, lack of knowledge about arterial graft spasm and management of this with mechanical dilatation was problematic. Observation of excellent, patent, atheroma-free RA grafts from the original series 2 decades later has prompted its reappearance as a coronary graft. Advantages include ease of procurement, length $(18-22 \mathrm{~cm})$, robustness, versatility, excellent diameter appropriate to the coronaries, ease of constructing sequential anastomoses, potential for total arterial revascularization when used with the left ITA, especially as a T or Y graft, few infections and wound problems, suitable for use in patients with diabetes, and suitable for use in all ages, including the elderly, facilitating early ambulation. Proximally, its size generally allows direct anastomosis to the aorta or to an ITA. ${ }^{4}$

Crucial to successful RA use is optimal harvesting, preparation to maximize its perioperative and long-term efficacy, and minimizing harvest-related complications or impediments. These include wounds, cosmesis, neurologic (particularly sensory) abnormalities, finger/hand ischemia, graft damage (especially intimal), and spasm. Therefore,

\footnotetext{
From the Department Cardiothoracic Surgery, The Royal Melbourne Hospital, and Department of Surgery, The University of Melbourne, Melbourne, Australia.

Received for publication Sept 4, 2020; accepted for publication Oct 20, 2020; available ahead of print Nov 11, 2020.

Address for reprints: James Tatoulis, AM, MB, BS, MS, MD, FRACS, FRCST, FCSANZ, Department Cardiothoracic Surgery, The Royal Melbourne Hospital, Suite 28, Medical Centre, The Royal Melbourne Hospital, 300 Grattan St, Parkville, Melbourne, Australia 3050 (E-mail: james.tatoulis@mh.org.au).

JTCVS Techniques 2021;5:46-55

2666-2507

Copyright (C) 2020 The Authors. Published by Elsevier Inc. on behalf of The American Association for Thoracic Surgery. This is an open access article under the CC BY-NCND license (http://creativecommons.org/licenses/by-nc-nd/4.0/).

https://doi.org/10.1016/j.xjtc.2020.10.042
}
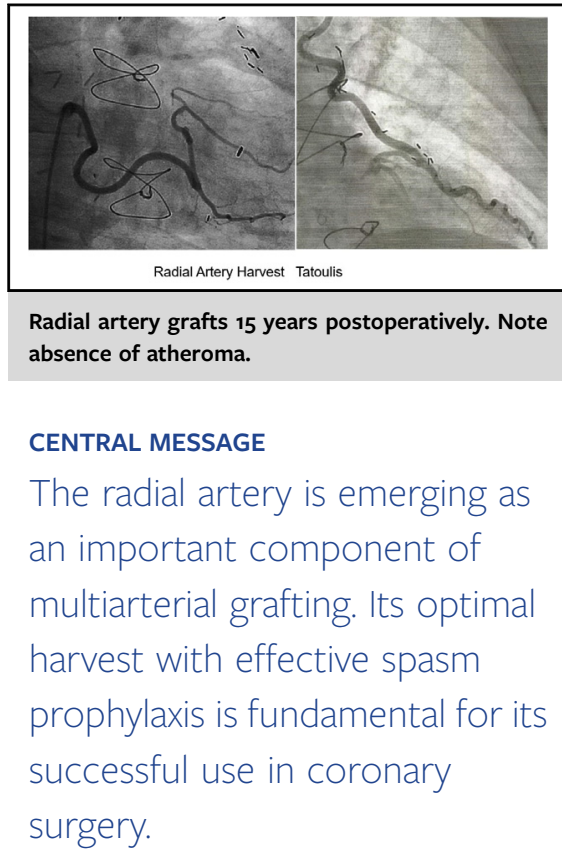

See Commentaries on pages 56,58 , and 60.

knowledge of RA anatomy, assessment of hand circulation, its morphologic and pharmacologic characteristics, relationships to relevant nerves, harvest strategies, and a reproducible technique to avoid these potential complications is mandatory.

\footnotetext{
Anatomy

The brachial artery bifurcates into the ulnar artery (UA) and RA at the elbow. The RA is usually smaller and fortuitously is not accompanied by any major nerves — unlike the UA (median nerve). The RA runs deep to the brachioradialis muscle and emerges between it and the flexor muscles approximately two-thirds of the way down the forearm, becoming superficial and easily accessible just above the wrist before its termination in the superficial and deep palmar arches (Figure 1).

Proximally, the recurrent RA arises $1 \mathrm{~cm}$ distal to the RA origin and runs laterally and proximally. The interosseous artery originates from the deeper aspect. In its proximal two-thirds, the RA lies in loose areolar tissue with few branches. The branches become more numerous in the distal third, particularly around the wrist. Branches on the
} 


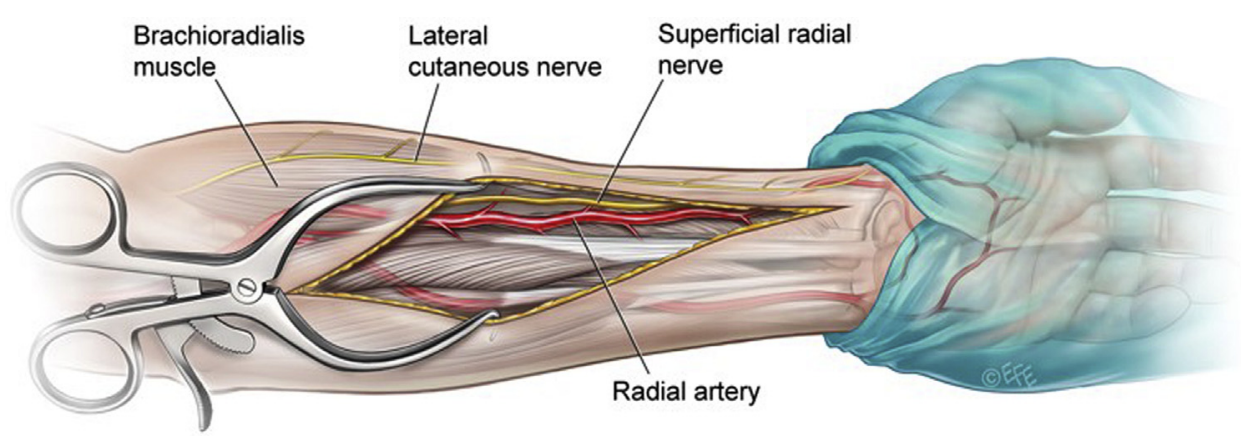

FIGURE 1. The left forearm showing the radial artery, ulnar artery, the superficial radial nerve closely related to the radial artery, and the more superficially and laterally placed lateral cutaneous nerve of the forearm.

volar (superficial) aspect of the RA are rare. As many as possible of the branches around the wrist should be preserved, especially if the whole length of the RA is not required.

\section{RA Anomalies}

Many RA anomalies have been described but are rare. ${ }^{5}$ The most important is that of a major lateral branch several centimeters above the wrist, effectively the functional continuation of the RA. A vestigial RA remains in the true anatomic continuation. This may lead to a false negative Allen test. Suspicion should be heightened if the hand fails to blanch at all when compressing the RA when performing the modified Allen test (MAT). Unless the main RA branch, coursing laterally, is compressed, one will not obtain a true assessment of UA dominance and capability of sustaining hand circulation.

\section{Contraindications to RA Use}

Absolute. RA dominance in the Allen test, significant trauma, collagen diseases, Raynaud's phenomenon, dialysis fistula, severe calcification, small size $(<2 \mathrm{~mm})$, and although unusual, sustained severe RA spasm with an effective internal diameter of $<2 \mathrm{~mm}$ despite topical and intraluminal vasodilators and fasciotomy.

Relative contraindications. Cold climate, renal failure with a potential need for an atrioventricular fistula, carpel tunnel syndrome, prior RA arterial monitoring, left breast/ axilla surgery, arm lymphedema, RA used for angiography or percutaneous coronary intervention (PCI), and skilled workers (eg, musicians).

\section{Assessment of the RA}

Five percent to $10 \%$ of RAs may not be appropriate or suitable to use. ${ }^{5-7}$ The MAT is the standard screening test for ensuring satisfactory hand circulation. We compress both RA and UA, have the patient clench his or her fist and relax it slowly 5 times, and then release the UA and observe reperfusion and blushing of the previously blanched thenar eminence, thumb, and the 2 adjacent fingers (Figure 2). Reperfusion within 10 seconds is satisfactory. Others have noted that the specificity of this test is maximal (>97\%), when a 5-second cutoff is used. ${ }^{6}$

Index finger plethysmography/oximetry combined with MAT adds a further level of certainty. ${ }^{7}$ Further, duplex ultrasound (DU) is useful in complementing the $\mathrm{MAT}^{8}$ and in determining RA diameter, calcification, atheroma, or prior damage (Figure 3). We avoid an RA with a distal internal luminal diameter $<2 \mathrm{~mm}$ because of potential inadequate flow. Calcification, when it occurs, is more apparent distally, and on the superficial aspect. Severe calcification is a contraindication to RA use (Figure 4). However, mild calcification may not be. There is no convincing evidence that calcification translates to later atheroma. It is mainly in the media, not in the intima, and does not seem to progress. The challenge of all calcification is in constructing a blood-tight, nondistorted distal anastomosis. If a shorter segment of RA will suffice, the distal RA should be left in situ. DU can evaluate a previously cannulated RA (ie, arterial monitoring for prior major surgery). There may be calcification or multiple channels. If a shorter RA segment will suffice, the distal 3 to $4 \mathrm{~cm}$ can be left in situ. DU can also determine forearm and digital artery flows and pressures to better define and establish safe thresholds that ensure adequate hand and finger circulation. ${ }^{7}$ Others have advocated the use of computed tomography scans, and occasionally RA angiography. We have not found these investigations to be necessary. We have successfully combined the MAT and index finger plethysmography/oximetry in more than 20,000 RA harvests using 10 seconds as a cutoff.

We have rarely used these more detailed techniques, and have encountered very rare finger and hand ischemia problems ( 2 episodes of fingertip ischemia early in our experience in 2 patients with scleroderma and 1 patient who required RA reconstruction with the vein graft 2 years later due to hand claudication with a new manual job in cooler conditions). ${ }^{4}$

\section{Histology/Morphology}

The RA is usually 2 to $2.2 \mathrm{~mm}$ in diameter distally and 3 to $3.5 \mathrm{~mm}$ proximally. Its muscular wall is apparent 

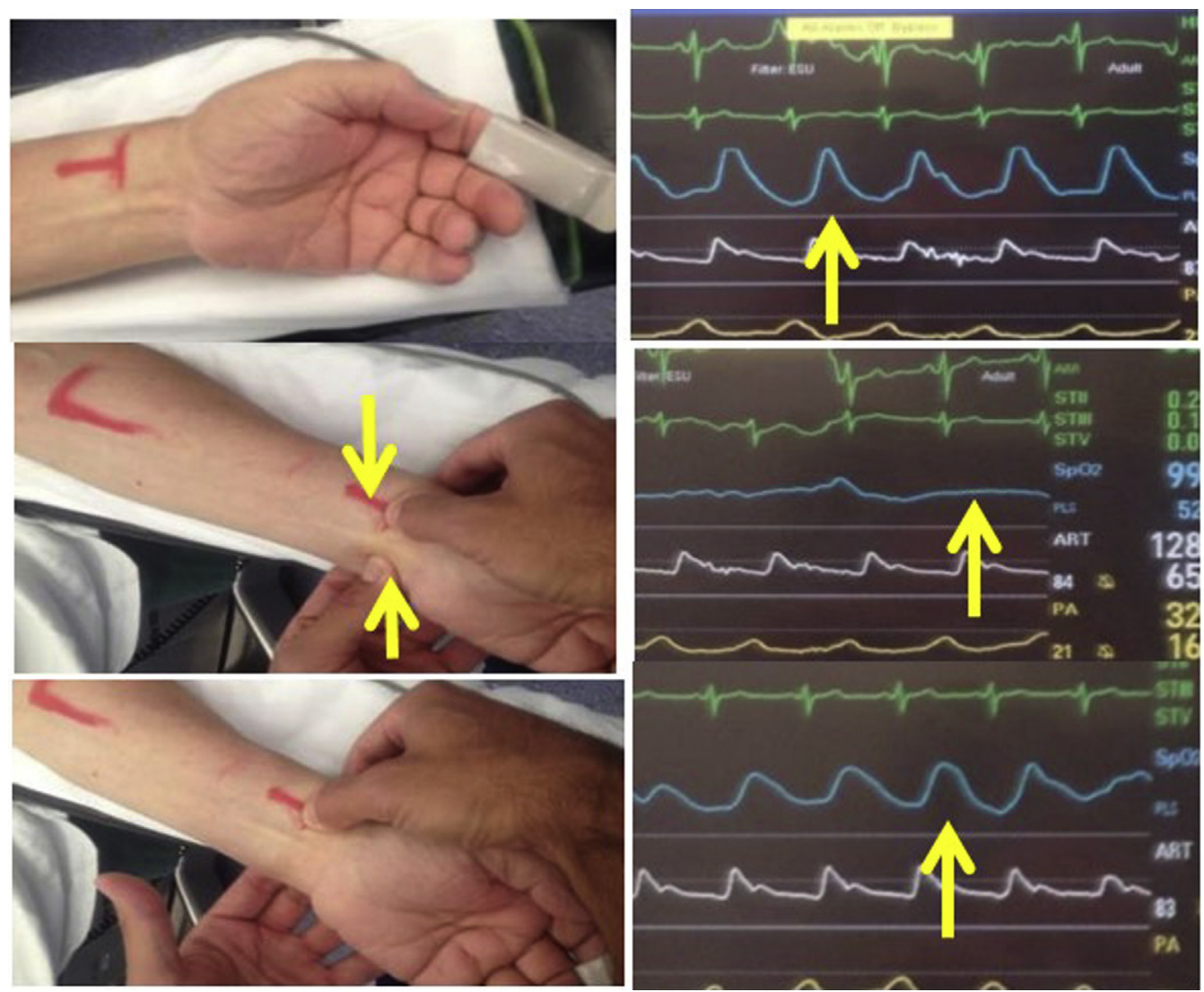

FIGURE 2. The modified Allen test used together with index finger plethysmography. Top panel, A normal pulse wave. Middle panel, An obliteration of the pulse wave when both the radial and ulnar arteries are occluded. Bottom panel, Reperfusion with an excellent return of the pulse wave in the index finger on release of the ulnar artery but continued compression of the radial artery.

macroscopically and its larger luminal size and vascular wall thickness is readily apparent when compared with the ITA. The smooth muscle component is approximately twice that of the ITA and is more prevalent distally. The intima is well developed, as is the internal elastic lamina, although it has many perforations. Intimal hyperplasia is common: Up to $76 \%$ of RAs compared with $5 \%$ for the ITA. $^{9}$

Calcification, when it occurs, tends to be in the media rather than intima, is more pronounced distally, and is especially relevant to older patients, patients with diabetes (incidence of $10 \%$ ), and those with renal failure (incidence of $27 \%)$. Atheroma in the RA is rare $(<5 \%$ incidence) ${ }^{9}$

\section{Spasm Prophylaxis}

The muscular component of the RA wall is up to twice that of the ITA (Figure 5). Spasm is much more prominent and must be recognized, pre-empted, and managed (the key problem in RA use in the 1970s). Numerous antispasm agents have been adopted. Intraoperatively, the following are commonly used: topically, intraluminally, and for storage solutions.
Papaverine. An opioid derivative with a strong vasodilatory action used topically, papaverine has an onset over minutes, a maximal effect at 1 hour lasting up to 8 hours. ${ }^{10}$ Its acidity ( $\mathrm{pH}$ of 4.4-4.8), is countered by use in a buffered solution such as Ringer's lactate. We use $30 \mathrm{mg}$ papaverine in $30 \mathrm{~mL}$ arterial heparinized blood at $37^{\circ} \mathrm{C}$. ${ }^{4}$

Nitroglycerin. A powerful vasodilator with a rapid onset of action, nitroglycerin (NTG) is extremely effective but has a short half-life. ${ }^{11}$ Its use, together with verapamil topically combines the powerful rapid onset vasodilating effect of NTG with the more sustained prolonged period of action of verapamil, up to 8 hours. ${ }^{11}$

Nitroprusside. Applied topically, nitroprusside is a powerful vasodilating drug, but is less popular because of its more profound systemic effects and less familiarity with its use.

Calcium channel blockers. Calcium channel blockers such as diltiazem, nifedipine, and verapamil are commonly used. Diltiazem has a relatively weak effect. Nifedipine is up to 15 times more powerful, but not readily available as an infusion. Verapamil is the best of these to be used in a topical/local milieu and is best combined with NTG (previously discussed). ${ }^{7,11,12}$ 

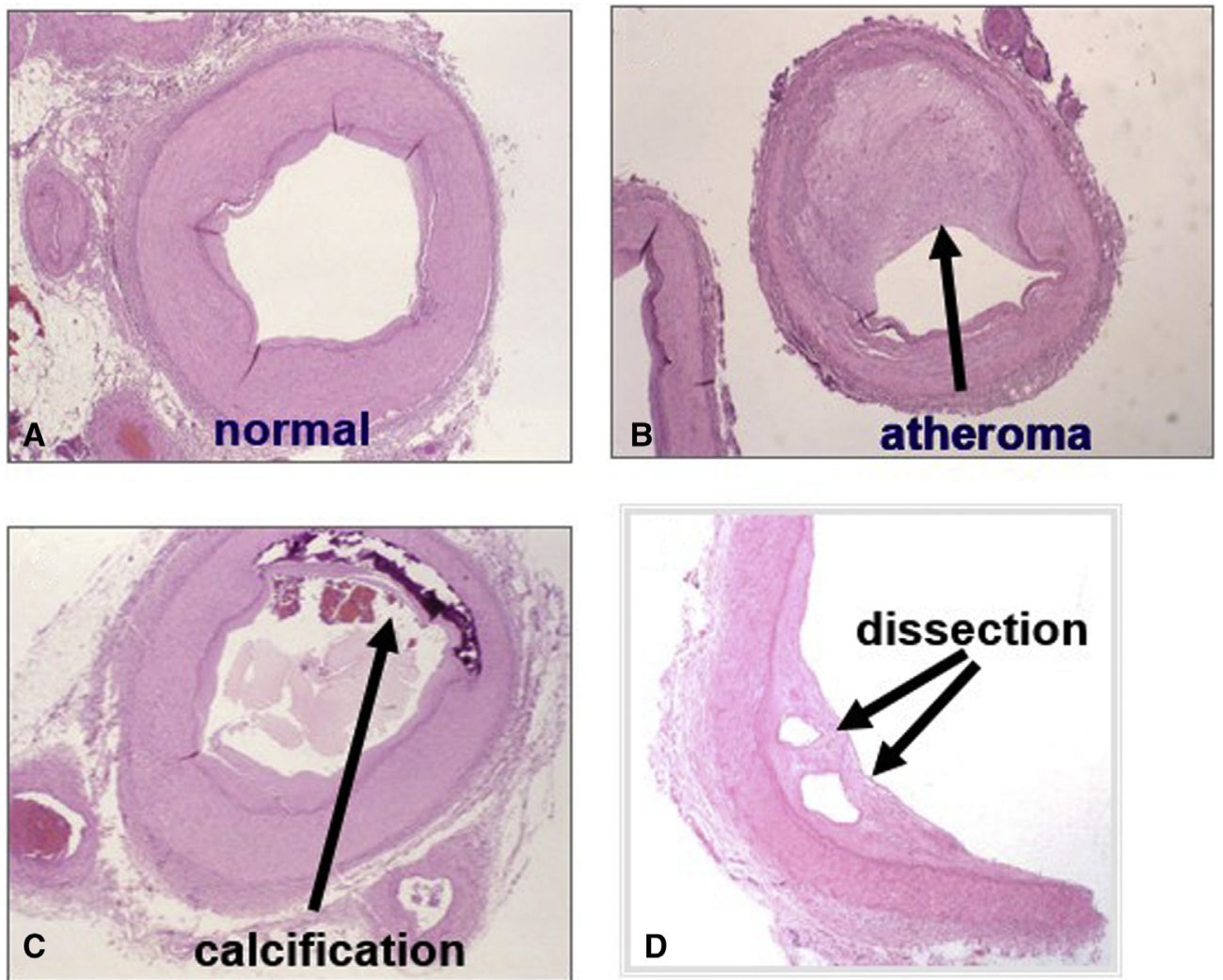

FIGURE 3. Histologic cross-sections showing pathology in the radial artery. A, Normal. B, Severe narrowing atheroma. C, Calcification that does not affect the lumen. D, Dissection in the subintimal layers from a prior radial artery line for blood pressure monitoring.

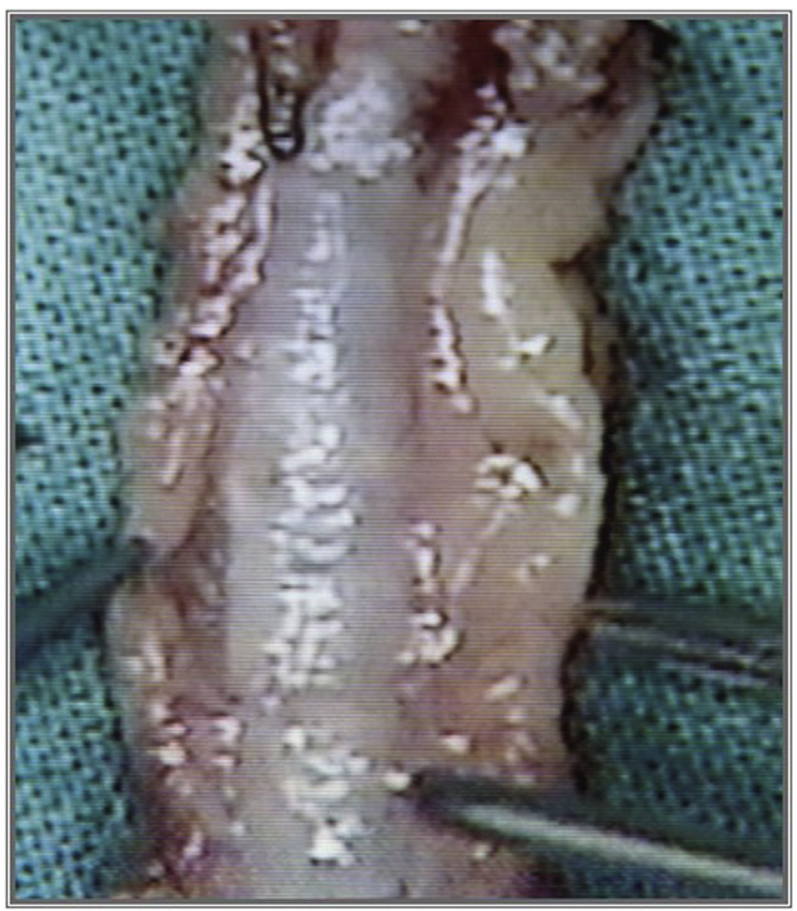

FIGURE 4. Completely, circumferentially calcified radial artery, not suitable for use.
Milrinone. Another powerful local and systemic vasodilator with a half-life of 2 hours. In addition to its topical use ( $5 \mathrm{mg}$ milrinone in $50 \mathrm{~mL}$ heparinized arterial blood), it can be used systemically in the perioperative period for cardiac support, enhancement of cardiac output, and ensuring arterial graft vasodilatation. ${ }^{11}$ Milrinone has been successfully over the past 15 years used as the vasodilator of choice (personal communication with Prof Brian F. Buxton, March 2005).

Phenoxybenzamine. A topical vasodilator, possibly more effective than papaverine, that is less acidic with a more prolonged period of action (up to 18 hours). An alphaadrenoceptor blocker, it is effective in blocking noradrenaline but not vasopressin, angiotensin, and thromboxane. It is best used with verapamil. ${ }^{7,11,13}$ However, phenoxybenzamine is poorly soluble and not universally available.

Other vasodilators. Multiple other vasodilators have been investigated, such as beta-agonists, prostacyclin, and angiotensin blockers, but these endeavors have been purely academic. Antiplatelet drugs may have a role as platelet activation from harvesting manipulation, and cardiopulmonary bypass may also be contributing factors to RA spasm. ${ }^{11}$

Large randomized trial data comparing the different topical, intraluminal, and storage solutions and clinical 

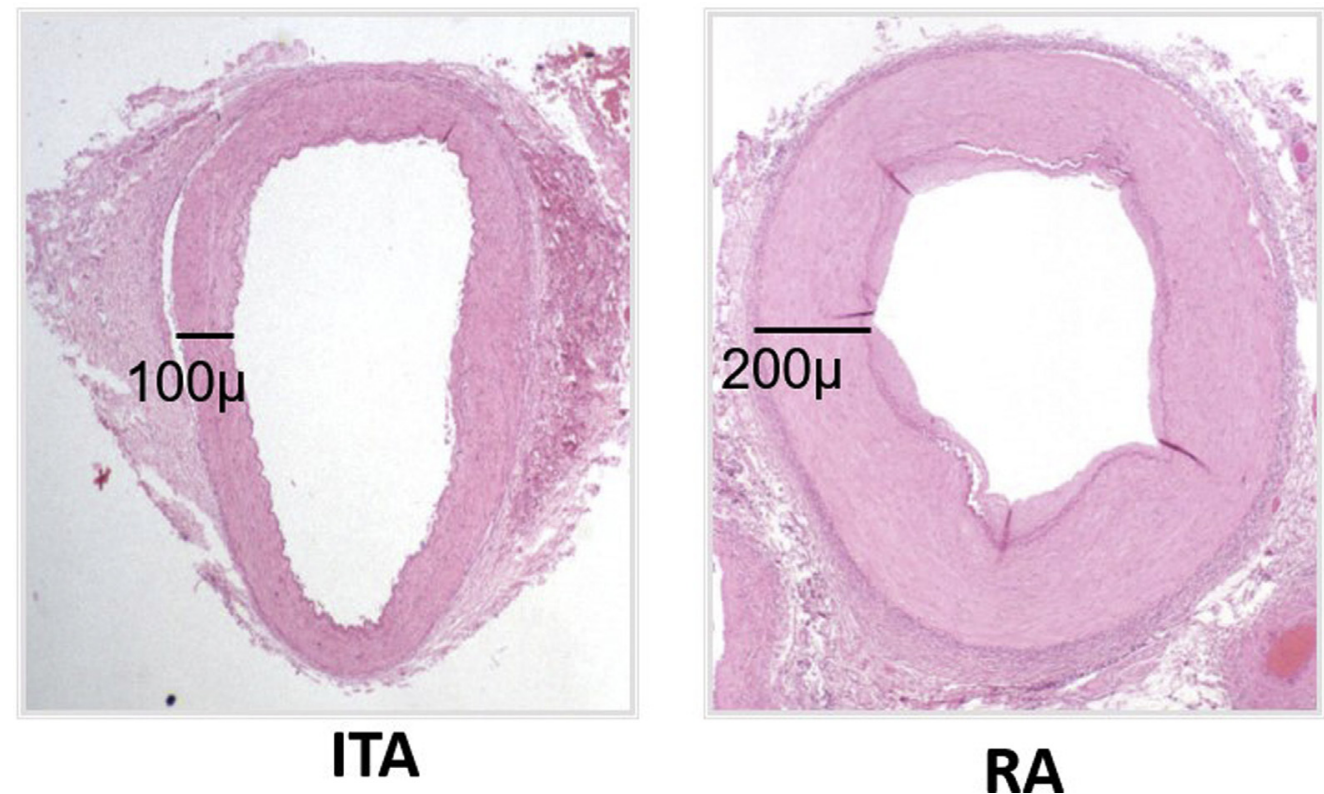

FIGURE 5. Comparative histologic cross-sections of the internal thoracic artery $(I T A)$ and radial artery $(R A)$ noting the significantly thicker muscular layer in the radial.

outcomes are lacking. Papaverine, NTG/verapamil, or diltiazem/nifedipine are more common in the practices that use the RA routinely.

\section{Perioperative Use}

There is no agreement about the continuation of RA and other arterial graft vasodilators in the immediate postoperative period. Some (including the author) use intravenous NTG (10-100 $\mu \mathrm{g} / \mathrm{min})$ for 24 hours postoperatively to maintain arterial graft dilatation, and for its cardiac effects, including reduction of preload and afterload, dilatation of coronary microcirculation and myocardium collaterals, and as a source of nitric oxide. This is continued with topical NTG, or oral nitrates for a further 2 to 3 days. Others continue with milrinon or diltiazem infusions for 24 to 48 hours. However, hypotension can be a problem. ${ }^{12}$

\section{Long-Term Anti-Spasm Prophylaxis}

Anecdotal evidence of RA graft spasm during the first few months postoperatively exists. ${ }^{4} \mathrm{~A}$ meta-analysis of RA RCTs found patients taking calcium channel blockers postoperatively had fewer adverse cardiac events and better long-term clinical outcomes. ${ }^{14}$ Hence, a calcium channel blocker for 6 months (eg, amlodipine 2.5-5 mg daily) may be beneficial.

\section{Other Factors}

Trauma and manipulation cause local vasospasm, as can exposure to cold-hence the need to maintain intra-operative topical solutions and environments as close to normothermia as possible.
Skeletonization allows for maximal dilatation and increased length by a $2 \mathrm{~cm}$ but is time consuming, and if done during harvest may inadvertently cause local trauma. Others prefer to incise the fascia particularly on the volar side for the entire length of the RA to allow maximal expansion and to protect against local constrictive fibrous bands. Skeletonization of the RA theoretically also enhances denervation and attenuates potential sympathetic responses and vasoconstriction.

We prefer an entire longitudinal fasciotomy and additional skeletonization for $2 \mathrm{~cm}$ at the distal end and 3 to $4 \mathrm{~cm}$ at the proximal ends. This allows maximal dilatation at the anastomotic points and protects against accidental incorporation of any fibrous bands that may distort the anastomosis.

A simple technique may help maximally dilate the RA during harvest. Specifically, once the RA is mobilized, the distal end is disconnected and antispam solution $(2-3 \mathrm{~mL})$ injected intraluminally with a blunt tip needle. The distal end is secured with a vascular clip, and the RA is allowed to beat against its occluded distal end for 5 to 10 minutes while the proximal branches are secured. This allows vasodilatation to occur so the surgeon can check for damage and bleeding. ${ }^{4}$

In the grafting sequence (on pump), usually the RA conduits are the first to be used to minimize their ex vivo location and maximally preserve endothelial integrity. Then vein grafts (if used) and finally the ITA(s). Before use, the RA should be stored in an appropriate antispam solution. Some leave the harvested ready-to-go RA in situ surrounded by vasodilator-soaked gauze until use. 
The reaction of the RA and other arterial grafts in the postoperative period to fluctuations in blood pressure and the use of vasoconstrictors such as noradrenaline, vasopressin, and metaraminol is not well documented nor well understood. Elevation of systolic blood pressure with noradrenaline will increase arterial graft flows; however, it is not clear if there is a threshold of alpha-adrenergic vasoconstrictor effect on the RA that then offsets this.

We manage the patient's clinical situation to ensure an excellent hemodynamic state with the cardiac index preferably $>2.5 \mathrm{~L} / \mathrm{min} / \mathrm{m}^{2}$, good urine output, and mixed venous saturation $>55 \%$. Noradrenaline is only used in urgent situations for hypotension, or when there is a significant systemic inflammatory response with a systemic vascular resistance index $<1500$ dyne-sec $/ \mathrm{cm}^{2} / \mathrm{m}^{2}$ and cardiac index $>3.0 \mathrm{~L} / \mathrm{min} / \mathrm{m}^{2}$.

\section{Vascular and Endothelial Integrity}

Vascular, especially intimal, damage resulting in shortterm acute thrombosis and long-term intimal hyperplasia are major concerns for patency and clinical outcomes. This has been widely studied with respect to saphenous vein graft harvest. Excessive manipulation, traction, distention, and acidic saline solutions are all deleterious. Endoscopic graft harvest, particularly early when the surgeon is inexperienced, has also been problematic.

Open radial artery harvesting (ORAH) is associated with less vascular trauma and preservation of histological intimal integrity. A no-touch technique, retention of the venae commitantes and associated perivascular tissues protects against such trauma. Elimination of electrocautery is also protective. $^{15}$

Techniques using clips and scissors or a harmonic scalpel that avoids the thermal damage that is associated with electrocautery are significant factors in minimizing vascular and endothelial damage. In addition, the ultrasonic effects of the harmonic scalpel may stimulate nitric oxide production in the RA endothelium, which contributes to vascular relaxation. $^{7,15}$

\section{RA Harvest}

ORAH versus endoscopic harvest. Endothelial trauma and its potential effects on graft patency remains the key controversy. For endoscopic radial artery harvesting (ERAH), early reports described significant vascular and endothelial abnormalities considering the learning experience and instrumentation in a confined space with thermal or ultrasonic vessel sealing, all potentially more traumatic. However, recent extensive experience in ERAH has shown excellent results with minimal or no discernible intimal damage in detailed microscopy, both of which have translated into excellent patency and clinical results. ${ }^{16}$

Studies with sophisticated immunofluorescent microscopy have shown equal or superior endothelial and intimal preservation with ERAH. ${ }^{17,18}$ Conversely others have found superior endothelial integrity with ORAH, ${ }^{18,19}$ and better preservation of endothelial-dependant vasodilatation. ${ }^{20}$ ORAH and ERAH are both applicable and after 25 years of evolution both techniques provide similar patency (approximately $90 \%$ at 6-10 years) and clinical outcomes. ${ }^{4,16,21}$ ERAH results in better cosmesis and fewer infections. Sensory abnormalities are similar and there is no reported difference by patients undergoing either technique at 12 months.

\section{General Technical Aspects}

- Commence proximal to the flexor crease at the wrist.

- A 3-cm incision to expose the RA distally to ensure its size, quality, and freedom from calcification before proceeding.

- Stay well clear of the ulnar artery proximally.

- Preserve the recurrent radial and the interosseous arteries if possible.

- If a shorter length is required, the proximal two-thirds to three-quarters of the RA is better because it is larger, has fewer branches, is less susceptible to calcification, has less smooth muscle, and preserves the anastomotic branches around the wrist that contribute to the Palmar arches and avoids prior cannulated sites.

- Excellent descriptions of ERAH, both with closed carbon dioxide and open systems, are provided by many authors. ${ }^{22}$

- The open technique that we have used since 1995 will briefly be described, and recommended for those commencing an RA program. In principle, it is identical to harvesting the saphenous vein.

- Surface markings are placed with a permanent marker, from the flexion creases proximal to the wrist, to the elbow flexion line.

- Usually the left (nondominant) forearm is prepped and draped and positioned $90^{\circ}$ to the table. The RA harvest proceeds simultaneously with sternotomy and left ITA harvest.

- A 3-cm incision is made distally over the radial to ensure its size and quality (noted above).

- A curvilinear incision, slightly medial to the anticipated course of the RA is made, predominantly to avoid the lateral cutaneous nerve of the forearm (Figure 6). The subcutaneous fat layer is opened with low power electrocautery.

- The fat and fascial tissues superficial to the RA are opened from the wrist to just below the elbow with a combination of scissors and low power electrocautery. Self-retaining retractors are placed. The fascial plane immediately adjacent to the RA is opened with scissors, especially mobilizing the RA, and its accompanying venae commitantes, medially, away from its position beneath the brachioradialis muscle. 

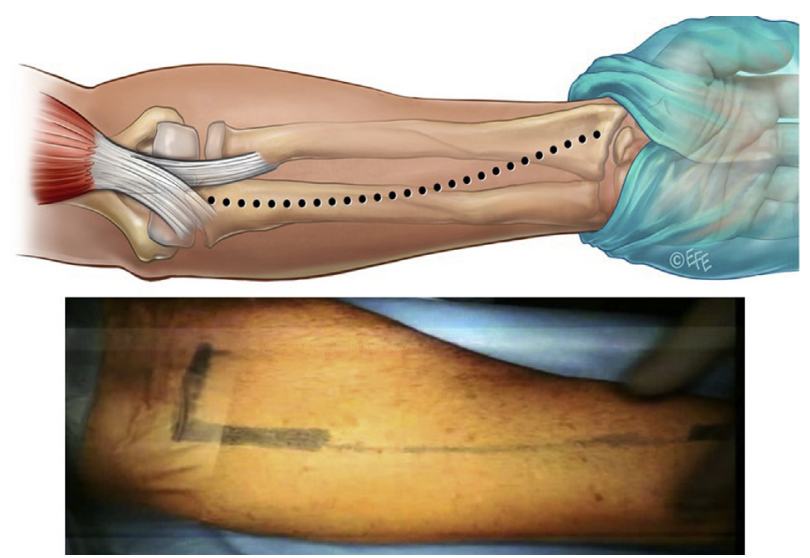

FIGURE 6. The curvilinear incision for open radial artery harvest, to avoid the lateral cutaneous nerve of the forearm.

- At this point 3 possible approaches can be employed:

- The individual branches can be identified and divided with scissors between clips (Figures 7 and 8);

- Individual branches are sealed with the harmonic scalpel; or alternatively,

- The tissues together with contained branches laterally, medially, and beneath are progressively sealed and divided en masse with the harmonic scalpel, resulting in a slightly wider pedicle (Figures 9-11).

- Papaverine or similar soaked gauze is constantly placed on the exposed RA pedicle.

- Distally, the venae commitantes are clipped and divided just proximal to the wrist. The distal RA is secured with 2 clips then divided, intraluminal antispasmodic is injected, and the distal end is clipped such that the RA beats against its occluded distal end while any further proximal branches are attended to. Care is taken to avoid the superficial radial nerve.

- Proximally, we preserve the interosseous and recurrent branches. There is always a venous plexus. The veins are divided between clips, preserving the deep draining veins if possible. The proximal RA is secured well clear

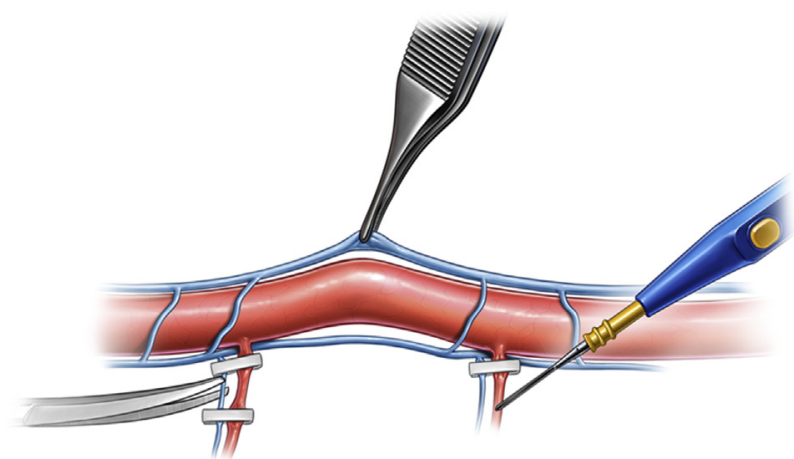

FIGURE 7. Atraumatic harvest of the radial artery using scissor and clip technique, or alternatively a clip on the radial side and cautery on the remnant.

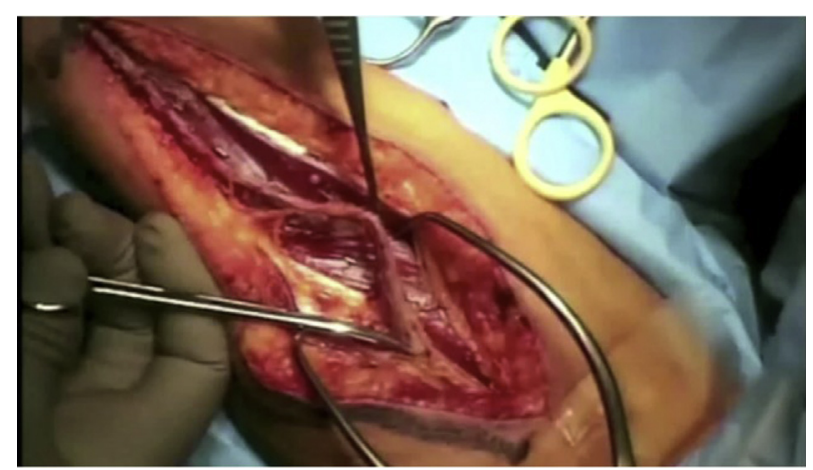

FIGURE 8. Radial artery exposed by the open technique. Note multiple branches distally but few proximally toward the elbow.

of the ulnar artery with 3 medium vascular clips (Figure 12). Alternatively, or in addition, a 4-0 polypropylene suture ligature is also used for security.

- Hemostasis is checked. We routinely use a small drain (24 hours) exiting laterally just below the elbow, taking care to avoid the cephalic vein.

- Subcutaneous and subcuticular closure is performed with absorbable sutures. A firm bandage is used and the arm brought to the side of the table and then the whole area is covered with a sterile, waterproof drape.

- The RA is then checked on the table, a longitudinal fasciotomy is made if appropriate, the distal end is prepared for anastomosis, then stored in the same vasodilating solution until use (Figures 13-15).

- Hand circulation is constantly monitored postoperatively by index finger plethysmography.

At the University of Melbourne hospitals, we have used this technique in $>20,000$ RA harvests, of which $30 \%$ have been bilateral. It is a technique readily mastered by surgical trainees who then can proceed to ERAH as required.

\section{Complications of RA Harvest}

There are no significant motor nerves accompanying the RA, hence motor dysfunction is rare. ${ }^{19,22}$ Sensory disturbances are common, more likely with ORAH, usually transient, related to traction on the superficial radial nerve, and edema affecting both the superficial radial nerve and the lateral cutaneous nerve of the forearm manifested as discomfort in the thenar eminence, thumb, and adjacent fingers. The incidence is up to $30 \%$, but has settled by 12 months. ${ }^{9,23}$ The cosmetic result with ERAH is better because it avoids the long incision; however, after 12 months most patients do not consider this to be a problem because the longitudinal incision heals well. ${ }^{4,24}$ Infection is rare, $<1 \%$, although again slightly more common with ORAH., ${ }^{4,16,23}$

Hematomas and seromas occur with both techniques, the incidence is low, $<1 \%$, and readily managed locally. With appropriate preoperative assessment, finger and hand 


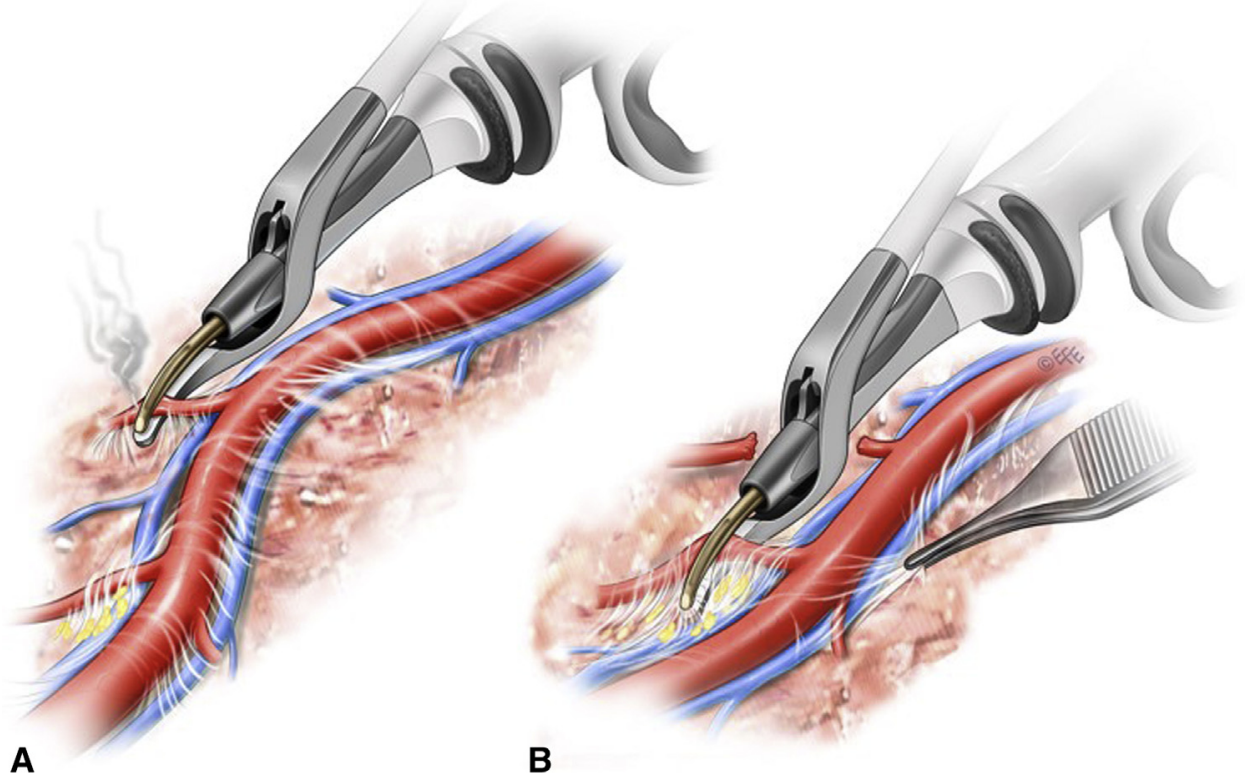

FIGURE 9. A, Harmonic scalpel sealing and dividing an individual radial artery branch. B, Harmonic scalpel sealing and dividing perivascular radial artery tissue en masse, including small arterial and venous branches.

ischemia is extremely rare. It should never occur if the MAT threshold is $\mathbf{5}$ seconds, and if the UA is not accidentally damaged.

\section{Functional Status of the Forearm and Hand}

Although power and utility in the affected hand may be initially reduced, by 12 months there is no discernible difference. $^{19,23,24}$
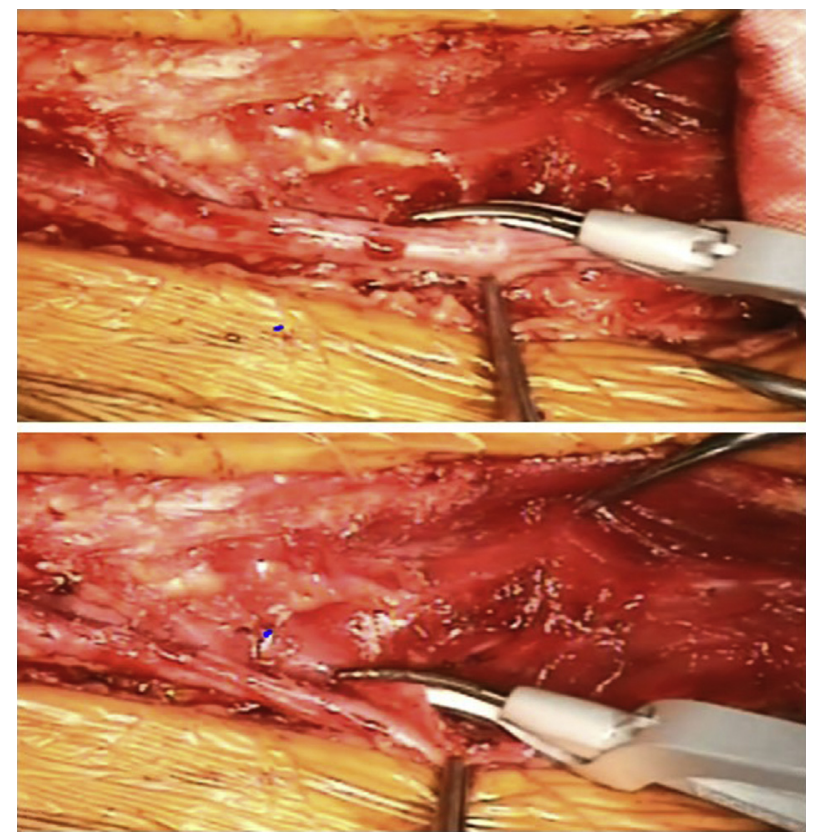

FIGURE 10. Operative photographs of Figure 9. Upper panel, Harmonic scalpel applied to an individual branch. Lower panel, Harmonic scalpel applied to the perivascular tissues en masse.

\section{Long-Term Vascularity of the Hand}

DU and angiographic studies have shown an increased number of collaterals in the forearm and palmar arches, enhancement of the hand circulation, and compensatory dilatation of the UA with an increase in diameter and flow of up to $20 \%$. The development of atheroma in the UA has been observed by some, but not by others in a 22-year follow-up. ${ }^{25}$ If correct assessment of the hand circulation has been made preoperatively there is rarely a subsequent ischemic issue.

\section{RA Previously Used for Angiography and PCI}

With the increasing use of especially the right RA for angiography and PCI, it is important to be aware of potential problems. Instrumentation for angiography results in occlusion $(5 \%-10 \%)$, endothelial disruption or intimal tears $(44 \%)$, dissection ( $45 \%-67 \%)$ noted by optical coherence tomography, intimal hyperplasia $(73 \%-80 \%)$, and diffuse narrowing $(22 \%)$, adjacent perivascular inflammation, and tissue necrosis (26\%-33\%). These changes are

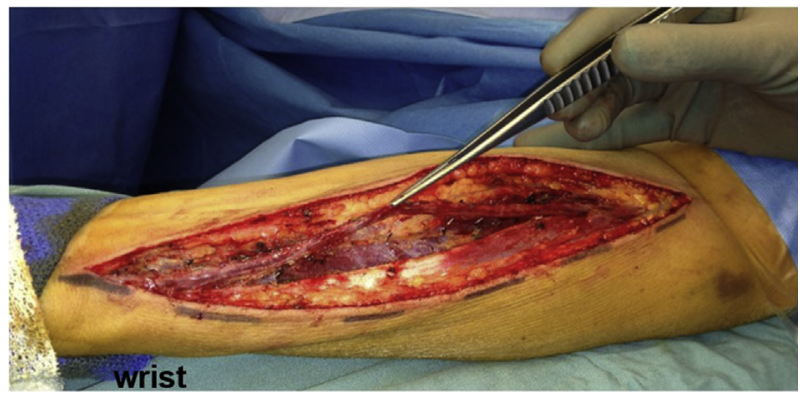

FIGURE 11. Radial artery after complete mobilization. 


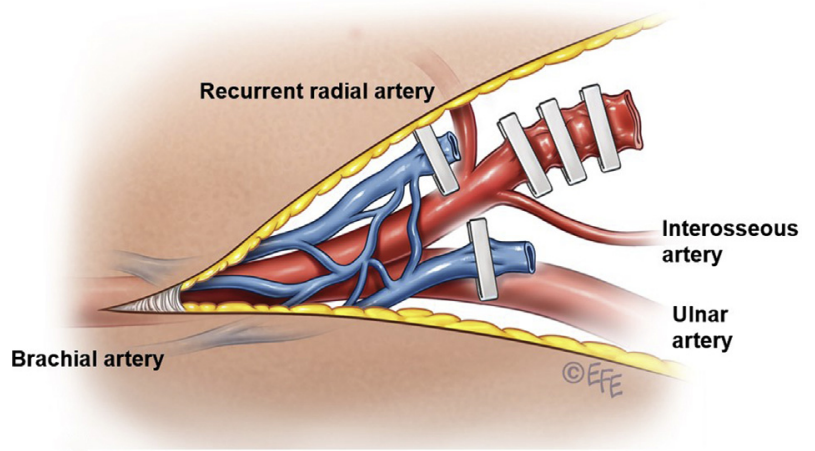

FIGURE 12. Proximal control of the radial artery. Three medium vascular clips placed just distal to the recurrent radial and interosseous arteries, well clear of the ulnar artery. The veins that come together as a venous plexus are separately clipped and divided.

most pronounced within 3 to $4 \mathrm{~cm}$ of the RA puncture, and in keeping with the length of the sheath used. ${ }^{26-29}$ Endothelial dysfunction along the whole length of the RA occurs with failure of appropriate vascular responses, particularly to vasodilators. ${ }^{26,27}$ These changes may last for at least 3 months.

Where the proximal recently instrumented RA was used for coronary artery bypass grafting, patency rates were significantly lower- $77 \%$ versus $98 \%$ at 1 month, and $59 \%$ versus $78 \%$ at 12 months. $^{28}$ An instrumented RA should be avoided. If it cannot; for example, because of conduit shortage, then a delay of 3 months is recommended. $^{26,28}$

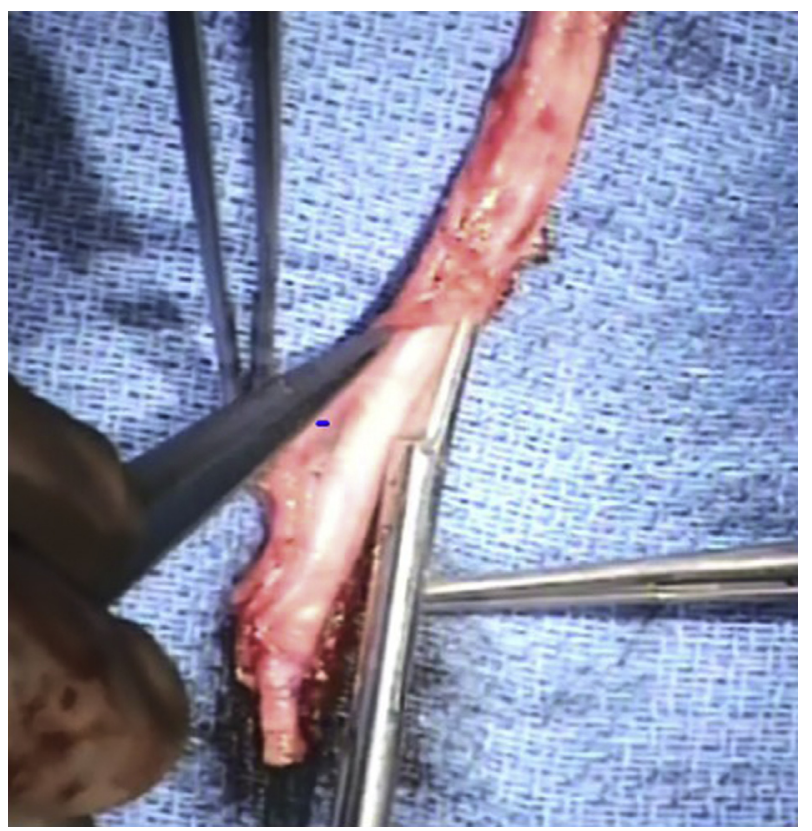

FIGURE 13. Fasciotomy to aid with maximal dilatation of the radial artery and to prevent any kinking or distortion by fascial bands.

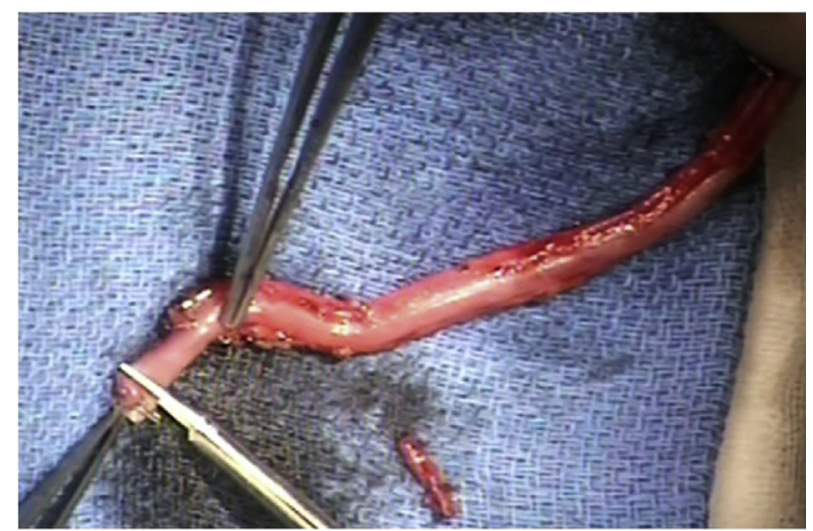

FIGURE 14. Preparation of the distal end for anastomosis. Note the distal 2 to $3 \mathrm{~cm}$ have been skeletonized.

\section{Patency and Clinical Results}

RA patency is up to $90 \%$ at 10 years, and up to $84 \%$ at 20 years, and even higher when used to graft tightly stenosed or occluded vessels. RA patency is identical to that of ITA(s) when grafted to the same vessels under the same conditions. ${ }^{4,30}$ All observational and RCT reports have shown RA patency to be superior to saphenous vein graft patency. ${ }^{1,4,14}$ The RA remains free of atheroma in the long-term and adopts morphologic changes over time. Its wall becomes less thickened and more in keeping with the ITA. Long-term survival with RA use (usually together with left ITA as part of a MAG procedure) is approximately $80 \%$ at 10 years, depending on the original patient cohort and age-generally $5 \%$ to $10 \%$ better than comparable patients with left ITA plus saphenous vein grafting at 10 years.

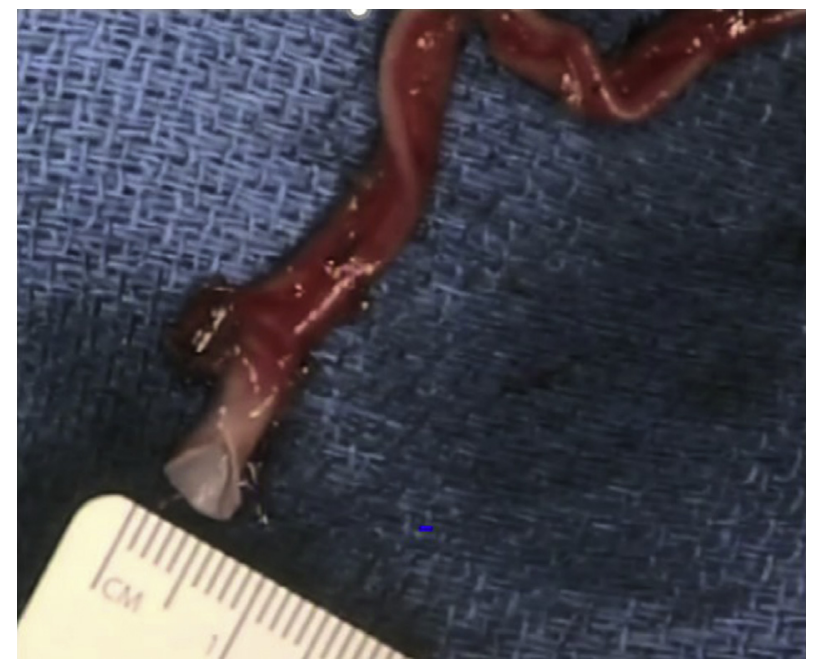

FIGURE 15. The skeletonized distal end of the radial artery prepared for anastomosis. 


\section{CONCLUSIONS}

The RA has many benefits and is available in $95 \%$ of patients. It can be harvested simultaneously with the left ITA using techniques identical to those for saphenous vein grafting. It is long, robust, easy to use, and ideal for sequential anastomoses. It produces nitric oxide and does not develop atheroma long-term. Wound problems are rare, leg incisions are avoided, and earlier ambulation is beneficial for elderly patients. Spasm prophylaxis is mandatory and avoidance of competitive flow is important. It allows MAG, including in patients with diabetes and obesity, and is associated with excellent short-term and superior long-term outcomes. The RA is the best strategy to enhance the uptake of MAG in a cautious, responsible, and progressive manner.

\section{Conflict of Interest Statement}

The author reported no conflicts of interest.

The Journal policy requires editors and reviewers to disclose conflicts of interest and to decline handling or reviewing manuscripts for which they may have a conflict of interest. The editors and reviewers of this article have no conflicts of interest.

The author thanks Dr Levent Efe for the illustrations and Ms Carol Maguire for assisting with the preparation of the manuscript.

\section{References}

1. Gaudino M, Benedetto U, Fremes S, Ballman K, Biondi-Zoccai G, Sedrakyan A, et al. Association of radial artery grafter versus saphenous vein graft with long term cardiovascular outcomes among patients undergoing coronary artery bypass grafting. A systematic review and meta-analysis. JAMA. 2020;324:179-87.

2. Taggart DP, Gaudino MF, Gerry S, Gray A, Lees B, Dimagli A, et al. Effect of total arterial grafting in the arterial revascularization trial. J Thorac Cardiovasc Surg. March 19, 2020 [Epub ahead of print].

3. Buxton BF, Shi WY, Tatoulis J, Fuller JA, Rosalion A, Hayward PA. Total arterial revascularization with internal thoracic and radial artery grafts in triple-vessel coronary artery disease is associated with improved survival. J Thorac Cardiovasc Surg. 2014;148:1238-43.

4. Tatoulis J, Buxton BF, Fuller JA, Meswani M, Theodore S, Powar N, et al. Long term patency of 1,108 radial arterial coronary angiograms over 10 years. Ann Thorac Surg. 2009;88:23-9.

5. Ruengsakulrach P, Eizenberg N, Fahrer C, Fahrer M, Buxton BF. Surgical implications of variations in hand collateral circulation: anatomy revisited. J Thorac Cardiovasc Surg. 2001;122:682-6.

6. Kohonen M, Teerenhovi O, Terho T, Laurikka J, Tarkka M. Is the Allen test reliable enough? Eur J Cardiothorac Surg. 2007;32:902-5.

7. Gaudino MF, Fremes S, Schwann TA, Tatoulis J, Wingo M, Tranbaugh RF. Technical aspects of the use of the radial artery in coronary artery bypass surgery. Ann Thorac Surg. 2019;108:613-23.

8. Ruengsakulrach P, Brooks M, Hare DL, Gordon I, Buxton BF. Preoperative assessment of hand circulation by means of Doppler ultrasonography and the modified Allen's test. J Thorac Cardiovasc Surg. 2001;121:526-31.

9. Baikoussis NG, Papakonstantinou NA, Apostolakis E. Radial artery as graft for coronary artery bypass surgery: advantages and disadvantages for its usage focused on structural and biological characteristics. J Cardiol. 2014;63: 321-8.

10. Harrison WE, Mellor AJ, Clark J, Singer DRJ. Vasodilator pre-treatment of human radial arteries. Eur Heart J. 2001;22:2209-16.
11. He GW, Taggart DP. Anti-spastic management in arterial grafts in coronary artery bypass grafting surgery. Ann Thorac Surg. 2016;102:659-68.

12. Schwann TA, Gaudino M, Baldawi M, Tranbaugh RF, Schwann AN, Habib R Optimal management of the radial artery grafts in CABG: patient and target vessel selection and antispam therapy. J Card Surg. 2018;33:205-12.

13. Rehman SM, Yi G, Taggart DP. The radial artery: current concepts on its use in coronary artery revascularization. Ann Thorac Surg. 2013;96:1900-9.

14. Gaudino MF, Benedetto U, Fremes S, Biondi-Zoccai G, Sedrakyan A, Puskas JD, et al. Radial artery or saphenous vein graft in coronary artery bypass surgery. $N$ Engl J Med. 2018:378:2069-77.

15. Hata M, Shiono M, Sezai A. Determining the best procedure for radial artery harvest: prospective randomized trial for early post-harvest complications. J Thorac Cardiovasc Surg. 2005;129:885-9.

16. Ferdinand FD, MacDonald JK, Balkhy HH, Bisleri G, Hwang HY, Northrup P et al. Endoscopic conduit harvest in coronary artery bypass grafting surgery: an ISMICS systematic review and consensus conference statements. Innovations 2017;12:301-19.

17. Nowicki M, Misterski M, Malinska A, Perek B, Ostalska-Nowicka D Jemielity M, et al. Endothelial integrity of radial artery grafts harvested by minimally invasive surgery-immunohistochemical studies of CD31and endothelial nitric oxide synthase expressions: a randomized controlled trial. Eur J Cardiothorac Surg. 2011;39:471-7.

18. Van Linden A, Hecker F, Lehmann-Grube J, Arsalan M, Richter M, Matzke B, et al. Randomized trial of 2 endoscopic radial artery harvesting devices-immunofluorescence assessment. Ann Thorac Surg. 2020;110:897-902.

19. Royse AG, Royse CF, Shah P, Williams A, Kaushik S, Tatoulis J. Radial artery harvest technique use and functional outcome. Eur J Cardiothorac Surg. 1999; 15:186-93.

20. Gaudino MF, Lorusso R, Ohmes LB, Narula N, McIntire P, Gargiulo A, et al Open radial artery harvesting better preserves endothelial function compared to the endoscopic approach. Interact Cardiovasc Thorac Surg. 2019;29:561-7.

21. Dimitrova KR, Hoffman DM, Geller CM, DeCastro H, Dienstag B Tranbaugh RF. Endoscopic radial artery harvest produces equivalent and excellent mid-term patency compared to open harvest. Innovations. 2010;5:265-9.

22. Blitz A, Osterday RM, Brodman RF. Harvesting the radial artery. Ann Cardiothorac Surg. 2013;2:533-42.

23. Holman WL, Davies JE, Lin J, Wang Y, Goldman S, Bakaeen F, et al. Consequences of radial artery harvest: results of a prospective randomized multicenter trial. JAMA Surg. 2013;148:1020-3.

24. Zhu YY, Hayward PA, Hadinata IE, Matalanis G, Buxton BF, Stewart AG, et al Long-term impact of radial artery harvest on forearm function and symptoms: a comparison with leg vein. J Thorac Cardiovasc Surg. 2013;145:412-9.

25. Royse AG, O'Donnell MJ, Mocioaca L. Does radial artery harvest for coronary surgery compromise forearm blood flow to 22 years postoperatively? J Am Coll Cardiol. 2018;72:1981-2.

26. Lim LM, Galvin SD, Javid M, Matalanis G. Should the radial artery be used as a bypass graft following radial access coronary angiography. Interact Cardiovasc Thorac Surg. 2014;18:219-24.

27. Mounsey CA, Mawhinney JA, Werner RS, Taggart DP. Does previous transradia catheterization preclude use of the radial artery as a conduit in coronary artery bypass surgery? Circulation. 2016;134:681-8.

28. Ruzieh M, Moza A, Bangalore BS, Schwann TA, Tinkel JL. Effects of transradia catheterization on patency rates of radial arteries used as a conduit for coronary bypass. Heart Lung Circ. 2017;26:296-300.

29. Yonetsu T, Kakuta T, Lee T, Takayama K, Kakita K, Iwamoto T, et al. Assessment of acute injuries and chronic intimal thickening of the radial artery after transradial coronary intervention by optical coherence tomography. Eur Heart J. 2010; $31: 1608-15$

30. Gaudino M, Tondi P, Benedetto U, Milazzo V, Flore R, Glieca F, et al. Radial artery as a coronary artery bypass conduit. 20-Year results. J Am Coll Cardiol. 2016;68:603-10.

Key Words: coronary artery surgery, radial artery graft, radial artery harvest, radial artery anatomy, pharmacology, physiology 